\section{Sino-Japanese collaboration}

Tokyo

IN the wake of successful cooperation between the United States and Japan in oceanography, Japan's Science and Technology Agency has recently revealed plans for joint research with China in a multi-million dollar long-term study of the East China Sea and the Kuroshio, a huge warm ocean current in the Western Pacific that affects fishing, weather and shipping.

Although details are still under negotiation, the project will start in March 1986 and run for seven years. The chief participants will be Japan's fishery, meteoroological and maritime safety agencies and China's National Bureau of Oceanography.

The project, which was proposed by China in "vague" terms two years ago and put into more concrete form by Japan, will follow on from a 10-year study of the Kuroshio sponsored by the Science and Technology Agency. That survey, the Kuroshio Exploitation and Utilization Research (KER) project, is due to end next year but has only covered a small area of the East China Sea, a politically sensitive region for oceanographic research because of its potential oil reservices.

The Kuroshio (black stream, black because of its low reflectivity) is a $100-\mathrm{km}$ wide "river" of clear warm water originating east of the Philippines that flows north past the eastern coast of Taiwan and then winds its way along Japan's Pacific coast before turning abruptly out into the Pacific on meeting the southward-flowing cold Oyashio current. At this bend in the Kuroshio, the Kuroshio Extension, huge swirling eddies of warm water extending to depths of hundreds of metres break off from the main stream and head slowly north, often persisting for periods of more than a year before finally being absorbed into the Oyashio or reattached to the Kuroshio.

With a speed of 3-4 knots and a volume transport of 30-60 tons per second the Kuroshio represents a tremendous potential source of energy, a point not missed by energy-hungry Japan; one purpose of the KER project is to assess the viability of harnessing the Kuroshio's power. But the real power of the Kuroshio lies in its influence over Japan's fisheries.

In the East China Sea, the current creates one of the world's largest fishing grounds and is an important spawning area for several commercial fish such as sardines. According to a KER report published in March, vast numbers of fish eggs are spawned next to the temperature/salinity front of the Kuroshio and eggs and larvae are picked up by the current and transported hundreds of kilometres downstream to nursery grounds off the Pacific coast of Japan. In addition, fish such as tuna and bonito feed along the length of the Kuroshio and the warm eddies north of the

\section{France}

Kuroshio Extension can cause switches in the migration routes of several commercial fish such as Pacific saury. Japan's vast fishing industry thus has a tremendous vested interest in understanding the vicissitudes of the Kuroshio. In fact some large tuna fishing vessels are already equipped with automatic picture transmission equipment for receiving and processing real-time infrared satellite images of the Kuroshio. As such equipment is beyond the resources of all but the largest fishing vessels (a terminal costs about $\$ 65,000$ ) the Japan Weather Association (JWA) introduced a satellite data service in October last year which provides HRPT (high resolution picture transmission) infrared imagery data in photographic or floppy disk form for as little as $\$ 4.60$.

Satellite-monitoring both of drifting buoys and sea-surface temperature will also form an important part of the joint project with China, according to Dr Hideo Nishida of the Hydrographic Department of the Maritime Safety Agency. The annual budget for Japan's contribution to the project will be similar to that of KER, he said, more than Y100 million ( $\$ 0.4$ million).

At the same time as the Science and Technology Agency's project gets under way in the East China Sea, the Ministry of Education-affiliated Ocean Research Institute (ORI) of the University of Tokyo intends to tackle the other end of the Kuroshio, focusing attention on the warm core rings north of the Kuroshio Extension. Professor Takahisa Nemoto, head of the Plankton Division at ORI, announced at an international seminar here in Tokyo this week that a cruise of the institute's RV Hakuho Maru will study Kuroshio warm core rings in September 1987, while the institute's smaller research vessel, the Tansei Maru, will carry out preliminary studies in the same area in 1986.

David Swinbanks

\title{
Future of encyclopaedia in doubt
}

THE creation of a great new French encyclopaedia, mostly of the sciences, was announced by the present French government in 1982. It was to use all available new technologies (databanks, electronic access, video) as well as trhe more traditional ones (print) and it was to be the 20th century's answer to the Encyclopédie Diderot, the great enterprise of the Enlightenment to encompas all knowledge in a few fat volumes. Where it is now? Appealing, it seems, to the French public for a few sous. A new advertisement has appeared in Paris asking for "patrons" to invest in the new encylopaedia, which, until recently at least, has been unable to attract a French publisher willing to carry any financial risk.

The publishers North-Holland, it is hoped in Paris, may produce an English version, but the Commission Diderot, which is in charge of the 20th century masterwork, needs to raise another FF 10 million (around $£ 1$ million) to bring this "encyclopaedia of living questions" to the French. It will be interesting to see if the French will be willing to pay. So far the commission has a grant of some FF 750,000 from the ministries of education, research and culture, and has been promised a further FF 4 million from industry. That not being enough, the appeal appears to have been the only way forward.

So will the encyclopaedia, the brain-child of present education minister Jean-Pierre Chevènement (who was research minister at its launch), be worth a minimum of FF 100 investment? The French market is not large and the publishers' judgement should be respected. But FF 100 to be associated with a great project?

The encyclopaedia is certainly great: 200 volumes are expected by the end of 1989 , (01985 Nature Publishing Group and the first 20, involving 200 authors, are promised by April 1986. But its structure is novel and even contradictory. The principle is that "knowledge" is not fixed but changing; and moreover that at any time there can be many opinions on a subject. While this may be true of many ideas, there are also many of which it is not true. And it is difficult to see how a flux is to be fixed in encyclopaedic form.

In practice, the Commission Diderot's strategy was to send out a nation-wide "appeal for questions (this came before the appeal for funds), an appeal which led to a list of 350 (such as "will carbon-dioxide emissions alter the climate and by how much?') out of which the commission has selected some 50 for the first volumes. Some 80 per cent of the questions received were in the physical or biological sciences or in mathematics, and only 20 per cent in the social sciences (which surprised the commission secretariat). Answers to these questions by the 200 authors will form a resource, it is said in Paris, from which many kinds of publication may be drawn. A great deal depends, therefore, on these authors, who must produce texts which are "intelligible to all" and address all the fears and hopes raised by the subjects they cover.

According to Dominique Lecourt, shortly after he was appointed director of the project, the encyclopaedia is to be "a powerful instrument of liberation". It will also "reject any attempt to assemble the sum of all knowledge or to present it according to an apparently rational order". It is a mountainous and confusing task, and it must be asked if even France is large enough to face it - even with a few more sous.

Robert Walgate 